\title{
Molecular cloning and single nucleotide polymorphism analysis of IGF $2 a$ genes in the common carp (Cyprinus carpio)
}

\author{
S.Y. Su ${ }^{1,2}$, Z.J. Dong ${ }^{1,2,3}$, J.Q. Qu ${ }^{1}$, Z.Y. Liang ${ }^{1}$, J.Q. Zhang ${ }^{1}$, L.X. Ma ${ }^{1}$, \\ W. Liu ${ }^{1}$ P. Xu ${ }^{1,2}$ and X.H. Yuan ${ }^{1,2}$ \\ ${ }^{1}$ Wuxi Fisheries College, Nanjing Agricultural University, Wuxi, P.R. China \\ ${ }^{2}$ Key Laboratory of Freshwater Fisheries and Germplasm Resources Utilization, \\ Ministry of Agriculture, Freshwater Fisheries Research Center, \\ Chinese Academy of Fishery Sciences, Wuxi, P.R. China \\ ${ }^{3}$ College of Animal Science and Technology, Nanjing Agricultural University, \\ Nanjing, P.R. China \\ Corresponding author: P. Xu \\ E-mail: xup@ffrc.cn
}

Genet. Mol. Res. 11 (2): 1327-1340 (2012)

Received April 12, 2011

Accepted October 1, 2011

Published May 15, 2012

DOI http://dx.doi.org/10.4238/2012.May.15.3

\begin{abstract}
We studied whether two $I G F 2$ transcripts in common carp are similar to those found in zebrafish. The full-length $I G F 2 a$ cDNA contains a 5'-terminal untranslated region (UTR) of $105 \mathrm{bp}$, a 3'-terminal UTR of $1358 \mathrm{bp}$ and an open reading frame of $612 \mathrm{bp}$, which encodes a 206-amino acid protein. A 6614-bp full-length $I G F 2 a$ DNA molecule, including the 5'-flanking region, was isolated. Genomic DNA structure analysis revealed that the IGF2a gene contains four exons and three introns. Bioinformatics analysis indicated that the proteins encoded by $I G F 2 a$ genes in common carp have one signal peptide and one apparent transmembrane region. Bootstrapping was performed 1000 times to obtain support values for each branch. The common carp IGF2a were clustered in one group, while the outgroup (common carp IGF1) clustered in another group. We identified two new single nucleotide polymorphisms in intron 2 of the gene. One
\end{abstract}


polymorphism, A/N, can be found only in the Huanghe carp. The other polymorphism, $\mathrm{C} / \mathrm{N}$, can be found in both male Huanghe carp $\times$ female Heilongjiang carp and male Huanghe carp $\times$ female Jian carp. The second polymorphism, $\mathrm{C} / \mathrm{N}$, is primarily transferred from the male and may be related to heterosis.

Key words: Cyprinus carpio; DNA sequence; Cross-combination; SNP; IGF2a

\section{INTRODUCTION}

The first piscine insulin-like growth factor 2 (IGF2) cDNA to be cloned was that of rainbow trout (Shamblott and Chen, 1992). Since then, $I G F 2$ has been wholly or partially cloned in multiple species. Published gene and/or cDNA sequences for $I G F 2$ are now available for sea bream (Duguay et al., 1996), tilapia (Chen et al., 1997), zebrafish (Maures et al., 2002), rabbitfish (Ayson et al., 2002), carp (Tse et al., 2002), and chum salmon (Palamarchuk et al., 2002). In particular, 2 distinct genes encoding IGF2 peptides (IGF-2a, and $-2 b$ ) from zebrafish have been cloned and identified (Zou et al., 2009). The structures of these zebrafish IGF2 genes and their transcripts have also been determined (Zou et al., 2009). However, whether $2 I G F 2$ transcripts in common carp can also be found in zebrafish remains unknown, and therefore we were prompted to perform this study.

After removal of the leader sequence, the prohormone for IGF2, pro-IGF2, has been shown to contain a 5-domain structure (B-C-A-D-E). The A and B domains of IGF2 are highly conserved among vertebrates, with sequence identities generally between 70 and $90 \%$. The $\mathrm{C}$ domain of zebrafish IGF2b contains 9 residues whereas the $\mathrm{C}$ domain of dogfish shark IGF2 contains 8 residues, as is the case in mammals. The D domain of IGF2 appears to be well-conserved among fish and other vertebrates, with 5 of 6 residues exhibiting complete identity between humans and teleosts (Loffing-Cueni et al., 1999). The E domains of IGF2 prohormones are also generally longer than those of IGF1, containing as many as 98 residues (Ayson et al., 2002); the chum salmon, barramundi perch (Collet et al., 1997), and pufferfish IGF2 genes are composed of 4 exons and 3 introns, spanning approximately 7.9, 5.5, and 4.2 $\mathrm{kb}$ of genomic DNA, respectively (Palamarchuk et al., 2002). Zebrafish $I G F 2 b$ is $68 \%$ identical to human $I G F 2$, but shares only $65-68 \%$ identity with other fish orthologs; interestingly, its paralog (zebrafish IGF2a) is at the lower end of this spectrum (65\%), suggesting an ancient duplication of the IGF2 gene in this species.

Evidence from the mouse model has suggested that IGF2 may play an important role in regulating fetal growth; $I G F 2$ expression has also been reported to precede the onset of $I G F 1$ expression in mice (Rotwein, 1991). IGF2 mRNA is abundantly expressed in fetal rats, but the expression declines after birth in most tissues, with the exception of the choroid plexus and meninges, which show high expression (Bondy et al., 1990; Nilsson et al., 1996). The $I G F 2$ gene has also been shown to be abundantly expressed in both hepatic and nonhepatic tissues of juvenile and adult teleosts, including common carp (Tse et al., 2002; Vong et al., 2003), rainbow trout (Bobe et al., 2003; Chauvigne et al., 2003; Gabillard et al., 2003; Aegerter et al., 2004), zebrafish (Maures et al., 2002), daddy sculpin (Loffing-Cueni et al., 1999), tilapia (Caelers et al., 2003), sea bream (Perrot et al., 2000; Radaelli et al., 2003), and rabbitfish 
(Ayson et al., 2002). In addition, the $I G F 2$ polymorphism has generally been associated with growth, for example, in studies on pig (Stinckens et al., 2010) and tilapia (Yu et al., 2010).

Growth hormone treatment increased IGF2 mRNA content in hepatic and intestinal tissues (in vivo) and cultured hepatocytes (in vitro) in rainbow trout (Shamblott et al., 1995), and in brain, gills, intestine, kidney, and muscle of the common carp (Tse et al., 2002; Vong et al., 2003). In juvenile rainbow trout that were refed after a prolonged fasting period, $I G F 2$ mRNA levels in the myotomal muscle tissue were observed to increase in a time-dependent fashion for at least 34 days following refeeding (Chauvigne et al., 2003). IGF2 mRNA levels in refed fish were detectably higher (1.7-fold) than those in fasted fish after 34 days, although this response was much less robust than that seen with $I G F 1$ mRNA expression.

In this study, we cloned the full-length cDNAs of common carp IGF2a, obtained the genomic sequence of $I G F 2 a$, including the 5 ' flanking region, and analyzed it using bioinformatics. We also investigated the presence of a described mutation in IGF2 in all purebred and crossbred common carp.

\section{MATERIAL AND METHODS}

\section{Animals}

Four varieties of common carp (Jian carp, Huanghe carp, and their progeny and cross Huanghe $\operatorname{carp}^{\hat{}} \mathrm{x}$ Heilongjiang carp ) $($ sample size $=24)$ were selected from the cement tanks in Yixing, which are affiliated to the Freshwater Fisheries Research Center, Chinese Academy of Fishery Sciences. The fish were slaughtered and immediately dissected to collect 50-100 $\mathrm{mg}$ breast muscle, and dissected tissues were frozen in liquid nitrogen. Once in the laboratory, samples were conserved at $-80^{\circ} \mathrm{C}$ until RNA isolation was performed. This research has been carried out in accordance with the Code of Ethics of the World Medical Association.

\section{RNA isolation, RT-PCR for cDNA synthesis, and genomic DNA extraction}

Total RNA was isolated from the above-mentioned tissues by using TRIZOL reagent (Invitrogen, USA) according to manufacturer instructions. Single-strand cDNA synthesis was carried out from $1 \mu \mathrm{g}$ total RNA by reverse transcription. After denaturation at $70^{\circ} \mathrm{C}$ for 10 min, the RNA samples were incubated in $1 \mathrm{X}$ PCR buffer, $0.5 \mathrm{mM}$ deoxynucleoside triphosphate mix, $4 \mu \mathrm{M}$ oligo(dT) primer, $32 \mathrm{U}$ RNase, and $200 \mathrm{U}$ MMLV reverse transcriptase (Promega, USA) in a final volume of $25 \mu \mathrm{L}$. This reaction was maintained at $37^{\circ} \mathrm{C}$ for $50 \mathrm{~min}$, and the complementary DNA (cDNA) was stored at $-20^{\circ} \mathrm{C}$.

Genomic DNA was isolated from common carp blood by using the Universal Genomic DNA Extraction Kit Version 3.0 (TaKaRa, Japan) according to manufacturer instructions. The concentration and quality of the RNA and DNA were verified by spectrophotometry and electrophoresis on $1.0 \%$ agarose gel.

\section{PCR amplification, molecular cloning, and sequencing}

The sequences for the designed primers were obtained from GenBank ${ }^{\circledR}$ (http://www. ncbi.nlm.nih.gov/, NCBI, US National Library of Medicine, USA). Primer sequences were 
designed using the Primer 5.0 software and synthesized by TaKaRa (Table 1). The cDNA was amplified by PCR in a $10-\mu \mathrm{L}$ reaction volume containing $5 \mu \mathrm{L}$ Premix LA Taq Hot Start; 0.5 $\mu \mathrm{L}$ cDNA $(1 \mu \mathrm{g}) ; 0.2 \mu \mathrm{L}$ Primer F $(20 \mu \mathrm{M}) ; 0.2 \mu \mathrm{L}$ Primer $\mathrm{S}(20 \mu \mathrm{M})$, and $4.1 \mu \mathrm{L} \mathrm{ddH}_{2} \mathrm{O}$. The PCR products were separated on $1.0 \%$ agarose gel, purified with a PCR purification kit, and finally transformed into Escherichia coli. Plasmid DNA from isolated clones containing the insert was purified and finally subjected to cycle sequencing using fluorescent Big Dye technology (ABI automated sequencing). Genomic DNA fragments for $I G F 2$ were obtained from genomic DNA by pairs of specific primers used for the cDNA amplification. The 5' flanking region was obtained by a genome walking kit (TaKaRa). The DNA fragments were then cloned and sequenced.

\begin{tabular}{|c|c|c|c|}
\hline Oligo type & Oligo sequence (5'-3') & Length (bp) & $\operatorname{Tm}\left({ }^{\circ} \mathrm{C}\right)$ \\
\hline$I G F 2 a 1$ & $\begin{array}{l}\text { GACAGCCACAAGCATCACT } \\
\text { TTTCTCCATCTGCCTCCTA }\end{array}$ & 594 & 50 \\
\hline$I G F 2 a 2$ & $\begin{array}{l}\text { CTCTTCACAAGGACACCATA } \\
\text { AAGCTTCCATTGACTTTACT }\end{array}$ & 1600 & 55 \\
\hline$I G F 2 a 3$ & $\begin{array}{l}\text { GTGCCTCTTATTGCTTTCTACC } \\
\text { GAAACATCTCGCTCGGACTT }\end{array}$ & 690 & 56 \\
\hline
\end{tabular}

\section{Sequence analysis}

The analysis of nucleotide and amino acid sequences was conducted by the BLAST program at the National Center for Biotechnology Information (http://blast.ncbi.nlm.nih.gov/ Blast.cgi). The nucleotide and deduced amino acid sequences of 2 IGF2 cDNAs were analyzed by DNAssist 2.0, Clustalx 2, and Mega 4 softwares, and their protein structures were predicted using online analysis tools, i.e., PSORT II, SignalP, TMHMM, Neural Network Promoter Prediction, MethPrimer, TSSP, TFSEARCH, Proscan, PROSITE, and SOPMA.

\section{Single nucleotide polymorphism (SNP) analysis}

To confirm the polymorphisms, samples for the 4 cross-combinations were genotyped from IGF2 $a$ genes by using PCR primers designed for sequencing, and sequencing was performed according to standard methods. PCR was performed using $100 \mathrm{ng}$ genomic DNA with $0.6 \mathrm{pM}$ of each primer and Taq DNA polymerase (Invitrogen Life Technologies, Carlsbad, CA, USA) in a total volume of $25 \mu \mathrm{L}$. The following amplification conditions were used: an initial denaturation stage of $94^{\circ} \mathrm{C}$ for 3 min was followed by 35 cycles of denaturation at $94^{\circ} \mathrm{C}$ for $30 \mathrm{~s}$, annealing at $56^{\circ} \mathrm{C}$ for $20 \mathrm{~s}$, extension at $72^{\circ} \mathrm{C}$ for $50 \mathrm{~s}$, and a final extension at $72^{\circ} \mathrm{C}$ for $7 \mathrm{~min}$. PCR products were analyzed on a 1\% agarose gel and sequenced by ShangHai Majorbio Bio-Pharm Technology (China).

\section{Statistical analysis}

Data are reported as mean (SE) for each treatment and analyzed by ANOVA (general linear model-one-way analysis of variances) using the SAS 8.0 software. The means were compared at significance levels of 0.05 . 


\section{RESULTS}

\section{Isolation of the full-length IGF2 $a$ cDNA and DNA}

The full-length cDNA sequence (2075 bp) of IGF2a was isolated and deposited in GenBank $^{\circledR}$ under accession No. HM641129 (Figure 1). Its nucleotide sequence was significantly similar to that of zebrafish, as shown by a Basic Local Alignment Search Tool (BLAST) search in the NCBI database. The full-length cDNA contains a 5'-terminal untranslated region (UTR) of $105 \mathrm{bp}$, a 3'-terminal UTR of $1358 \mathrm{bp}$, and an open reading frame (ORF) of $612 \mathrm{bp}$, which encodes a protein of 206 amino acids with a calculated molecular weight of $23.1 \mathrm{kDa}$ and theoretical isoelectric point of 9.72 .

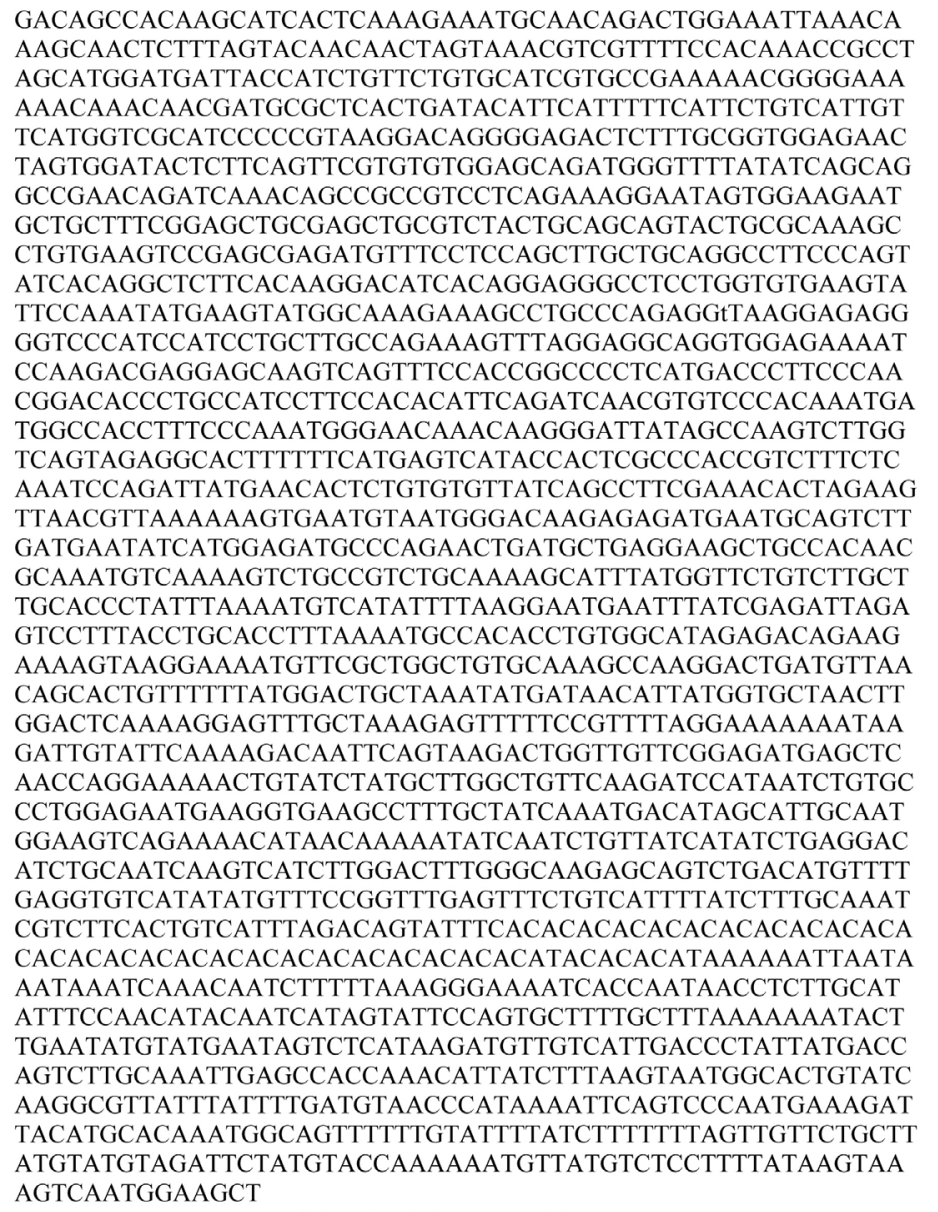

Figure 1. Full-length of $I G F 2 a$ cDNA in common carp.

A 6614-bp full-length IGF2a DNA, including the 5' flanking region, was isolated (Figure 2). 
A. DNA sequence of the common carp IGF2a

CTACGCGAATACATACTGCAACCCCAGTCATGTCATTGTCACTTTCTCTTAC CGTTGTTTGTCTTTGTTCAGGTACAGAAATTGAATAATTAAATGTAAAATAC CATTGCATAGTATTCACTGTATAAATTAAATATAATAATAACTTCTAATGCT ACAAAAGTTATTTAGTCAAGAAAAGTGAGTGATTCTCTCTCTCTCTCTCTCT CTCTCTTTTCTTGGATTAACATTAAGGAACCTACMKMMGCKAATAMATWM WGMRACCCCAGTCAT:G:T:CATTGTCWGGMTYYMWYWTAMYGWTRTWTS TTTYTYMMCTGTTTATGTTCACTTATGACATRACAGAGTTTTCGAGGATATT CACCCAAGCCGGTATTTTGAGATAAATAGTTTGCGCTGTGAACACACCTTCT TGCGCTTAAATGTTCAAATTGGCAAGATGTTGCAAAAACAGCAAATACCAT AGCAACATATGATAAAGAGTGAGGCTTTTCCACTGTCATTTTTTTTTTTAAG TTTAGGAGGTACAACATTAATATGCATTGGTTCATCTACTTCTTTGAGCACA AATTGTCCTTGCAAAGTAGCGTAATGGTTTTTTTGCACAGGTAAACRTTACT GTTCTAATAATAAGCTAGTGAGTGTAAGAGGGTGTTTGGTGTAAGGATTAG TGTGACTGAGTTACATGGGGAATGCAAATAGAGGTCTAAGCAGTTTCTTGA TGGCAGAGAGTGCCAAACGTCAAAAACAATATGTCTCAAATAGCCCAGTGG GTCACTGTATTCAGTGTATCAGATTACCATACTGTAGTTGTAAAAACAGTAC ACACATAACATAAGGATCATATCCAGAAAAATGCATTTATTTAATAAAGTTT TAGTTAATCCATTAATTAATTTAGTCACTGCCTCACTTTAACCGGAATAAGG TACAATCTCACTCATTTAAATTCGTTTTACAATGGCTTTATTACTTTGGACCA CTAGAGCGTGCTATAGTGTACTTGATACATGATACAACGTCACAATATTCAC ACACTATATTGAACAGTAACATTAAGTTTACATAAACAATTTTCCTTTGTGT ACATTGTCTCATACATTTTCACAGGCTATTTAATGAGAGGTGTTAGGCCTGT CTCTTTATAAAAATAACATATGAACTTTCAGTGTCTCTTTTCCTAATAAAATT AAAATGCTTATTTTTGTCCTTAAATCAATGATTGGTACTATTARTGTCCAGTT CAGACCATTTCCACTTTTAGAGGAAGGTAAAATGAGCACATTTTGCATGAC ACGGGCTGATGCTTCAGGCAGACAATGAAAGTGTTTTTGCTAAAGTTACATT ATGTCCAGTTTGAGGCATGTCAGGACATGTTGATTGTTCATTCATYTCCATC TAACACTTGTGTTTTTTAAGTACAAATTTTATGCATAATAATATATCTGTTTC GTTGTGTTCATTACTGGGTCGTATTCAGGGTATAAAACGGAATGAGTTGCTT TCTAAAGAAAGCATAAATCCTTTTAGGTTTCCCCTGAGATGTCGCGCGTGCA CAATGGGTCAATACTGTTGTCGTGAGAGTGAAATTTCWGCACGGTGTCTGT CTGCAGTCACTGGAATGTGATTGCAACCCCCTTTGTTATGGTGAGAAGCTGG ACGAATGTYCCCTTAATTAAAATTCCTCAGGCTGACCTGTTGCCAAAAGGTA TTTTAAAGCGGCGGCTATTTGACTAAGAATGCGCCTCGTCATCGGTGAGAGC AGGTAGCTACTCCATCAGCTGAGTGTCCGTTCAGACATAAACCAGTAGTGA GCGCTGCACTTTCACAATATTCTGGCATCAACACAAGTATTGTGTATATGAA CGGTTAATAAGACTGCTTTTCATCTGTGACTGAATCAGACGAGCAGAAAAC GTGTTTGGTGGTATTTATACAGTGTCAACAATAGAGAGAATTTGGGGAAAT CTAAATATTAAGTTTGAACATATTTACTCTTTGGGTTAAGGACAATGTTTGC TGCAGAATACTACTTCTGATTAAGAAAAGAGCATTGCAGTTCACATGCACA GTGAGCCCACTGGCAGTAATTGGAAAATAATTTCCGCGAATCGGATCTTTTO AACACTTCATTTCAAAGAAAGAGCTCTAAAAGAGAGAGAGAGAGAGAATA GTTACGTCATCACGTCAATCGTTCCAAATAAAGGCATTTCATATTCTAAATG TCTTCTTAATAAGAATGTTTGTTGTCATTTAGCATAATATAATCTAAGTATA ATTTGCAGAATCAAGAAACAACACTAAAAATGGATATCTTGGTTGAAATGC TATATGTTTATAAAACTGTCACAAAACAAGTTCTCGTTCAATGAGTCGGCGA GTTGTWGCCTCGAGAACCGTTCTTCTTACTAATTCAGTGTGCTGATTCTGGT CGGTTTTGTGCAGCGGTTCAACCAGTTCATTAAAAAAAAAGAAAAAAAAAA AAGATCCGACTCAAAAGAACCATTCGTTCACGAATCGGACATCGCTACTGG GCTGGGGGTGCGAGGGGCGGGTGTTGGTATAAATTTCCTCTCACTACATATG CCTTTGCCTGTCCTCTGAACTTTGAGACAGCCACAAGCATCACTCAAAGAAA TGCAACAGACTGGAAATTAAACAAAGCAACTCTTTAGTACAACAACTAGTA AACGTCGTTTTCCACAAACCGCCTAGCATGGATGATTACCATCTGTTCTGTG CATCGTGCCGAAAAACGGGGAAAAAACAAACAACggtaagagaaagtgacaatgacatg actggggttgcagtatgtattcgcgtagtttcatcgtttctacgtaattacagtttttgcatgtttaggaatattcatgacgatatgt aaaatttagagaaaagttaggagaatcatcattgttttaagcgtatagccgtttcttgattgtatcactgataagaagaatag cttctccacagttactttgaactttttgtgtcactctttggtcgcgtgattgaaatcagcacagtcacagcagtaacctctgtta acgatacggttgactacggation TACATTCATTTTTCATTCTGTCATTGTTCATGGTCGCATCCCCCGTAAGGACA TACATTCATTTTTCATTCTGTCATTGTTCATGGTCGCATCCCCCGTAAGGACA GAGCAGATGGGTTTTATATCAgtaagtgtaactcttacagtgctgtgtgatggttgtcaggaattctaaac atttacatagcgatctgtcttgtagaagtagtcacagtatggcattgtcatcagtcttgtctttcaaattgctgtttgtatagttcca tgtgcactaatgactgtcataatgagggtatttattaaagaggaaacgtgcctcttattgcttctaccaagtattcccagtga aagccattagtgctgttaattgctgttaaatgtcagtatttgggggaaacaaggaatttgtgtctgcaagttatttagttgtttgc aaaagatttctctctcttatgtcccetatattcctatcagatgacggagaacttceccettttgtacctctectgetgittcttatctt

Continued on next page

Figure 2. The nucleotide (HM6411291) (A) and the deduced amino acid sequence (B) of the common carp IGF2a. Nucleotide residues are numbered in the 5'- to 3'-direction, beginning with the 1st residue of the ATG triplet encoding the initiation codon for methionine. 
Figure 2. Continued.

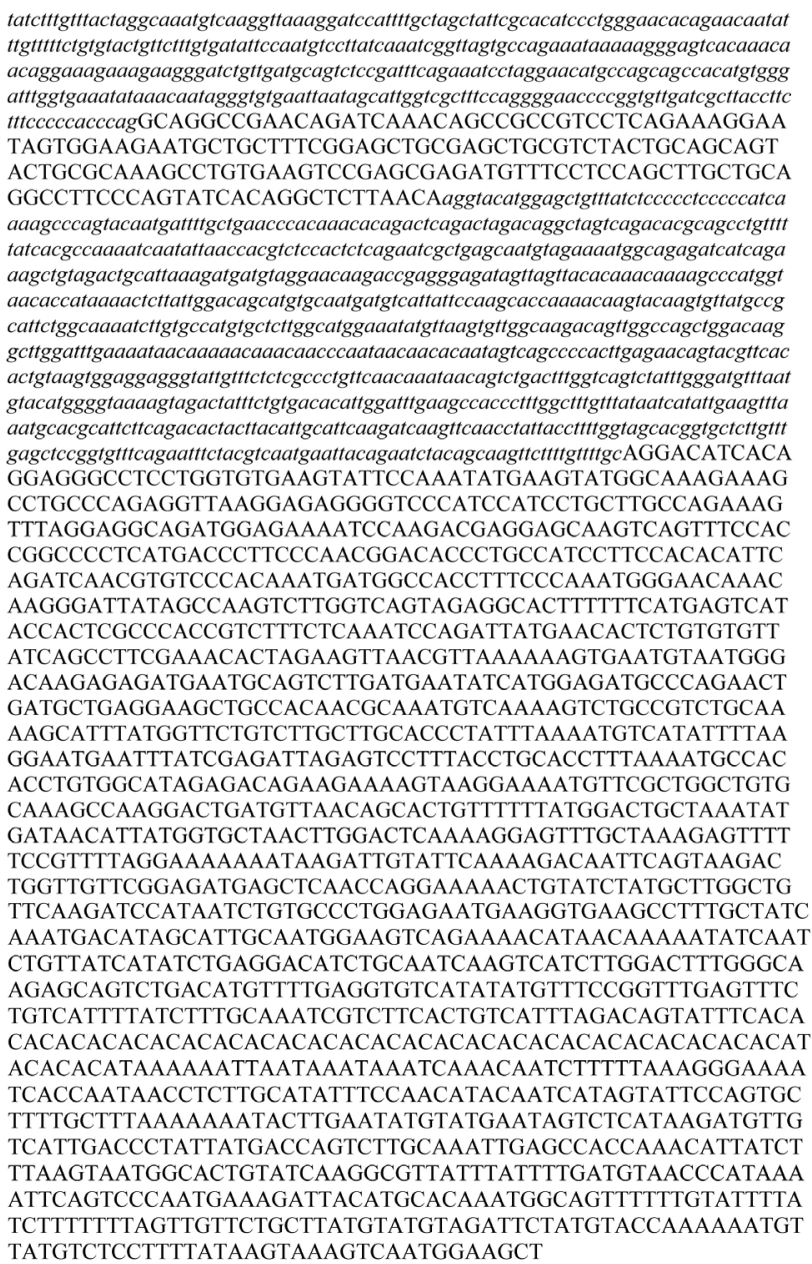

B. Protein sequence of the common carp IGF2a

MDDYHLFCASCRKTGKKQTTMRSLIHSFFILSLFMVASPVRTGETLCGGELVDT LQFVCGADGFYISRPNRSNSRRPQKGIVEECCFRSCELRLLQQYCAKPVKSERD VSSSLLQAFPVSQALHKDITGGPPGVKYSKYEVWQRKPAQRLRRGVPSILLA RKFRRQVEKIQDEEQVSFHRPLMTLPNGHPAILPHIQINVSHK

By comparing the sequence isolated from genomic DNA with the cDNA sequence of $I G F 2$ (NM 131433), we showed that there were 4 exons and 3 introns in the $I G F 2 a$ fragment (Figure $\overline{3}$ ). The exon-intron structure of the $I G F 2 a$ gene was verified experimentally by RT-PCR with primers located in different exons of the gene. The corresponding 206 amino acids encoded by the cDNA also had high similarity to other known IGF2a protein sequences (Figure 2B). The deduced protein sequence included 17 positively charged residues (Arg and Lys) and 31 negatively charged residues (Asp and Glu), with a net negative charge. BLAST analysis showed that the amino acid sequence of IGF2a shared low similarity with that of 
IGF2b, with a 55\% identity between IGF2a and IGF2b. Amino acid sequence alignment between IGF2a and IGF2b is shown in Figure 3. The amino acid sequence comparison between IGF2a and IGF2b in common carp shows identities of $6.8,82.7,63.6,66.6,33.3$, and $6.3 \%$ in the signal peptide and $\mathrm{B}, \mathrm{C}, \mathrm{A}, \mathrm{D}$, and $\mathrm{E}$ domains, respectively.

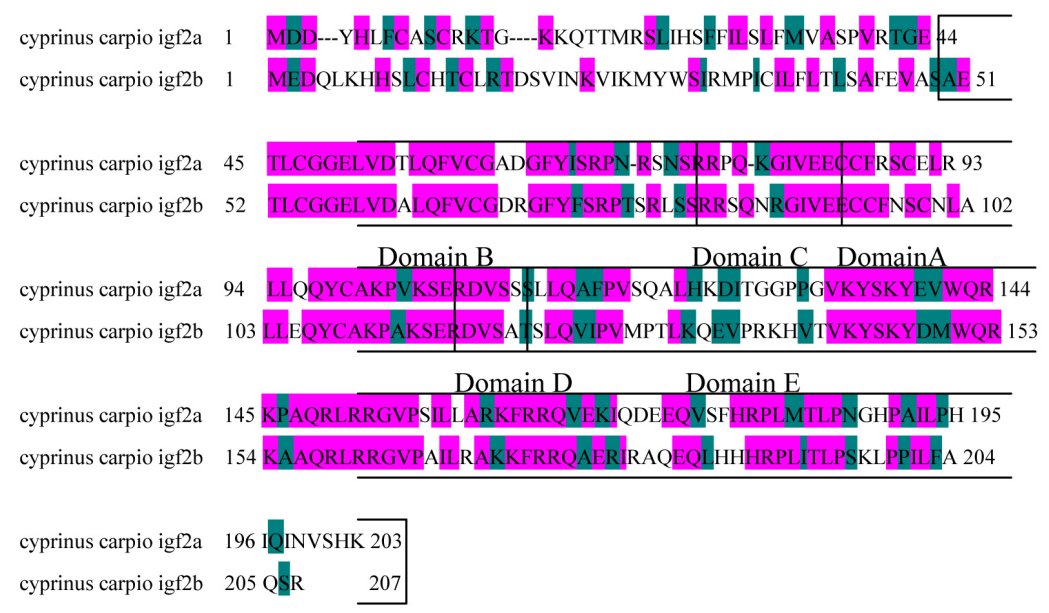

Figure 3. Comparison of deduced amino acid sequence of the IGF2a protein (HM641129) sequence and the IGF2b protein sequence in Cyprinus carpio.

\section{Phylogenetic analysis}

Phylogenetic analysis of IGF2a sequences was carried out (Figure 4). Bootstrap analysis with 1000 replicates was used to evaluate the significance of the nodes. The phylogenetic trees in Figure 4 were constructed by neighbor-joining algorithms using MEGA 4.1. Bootstrapping was performed 1000 times to obtain support values for each branch. Figure 4 shows that common carp IGF2a were clustered in one group, while the outgroup (common carp IGF1) was clustered in another group. Common carp was first clustered with zebrafish, then Carassius auratus, and mammal animals.

\section{Bioinformatics analysis}

A hydropathy analysis of the IGF2a amino acid sequence was performed using the ProtScale software (http://web.expasy.org/protscale/) [Swiss Institute of Bioinformatics]. One long stretch of hydrophobic residues was found to be present: 24 to 39 of the IGF2a polypeptide (Figure 5). The signal peptide sequence analysis using SignalP indicated that there is one signal peptide for IGF2a on position 34 . The most likely cleavage site is between positions 42 and 43. Transmembrane analysis was performed using TMHMM, and the result showed that there is one apparent transmembrane region in the IGF2a protein (Figure 5). The potential protein-modification sites of IGF2a were analyzed using PROSITE and yielded the following results: insulin family signature site (85-99 amino acids [aa]); bipartite nuclear localization signal profile (151-165 aa); protein kinase C phosphorylation sites (10-12, 14-16, 20-22, 74-76, 105-107, 201-203 aa); amidation site (14-17 aa); cAMP- and cGMP-dependent 
protein kinase phosphorylation sites (16-19 aa); N-glycosylation site (70-73, 199-202 aa); casein kinase II phosphorylation sites (105-108, 137-140 aa), and N-myristoylation sites (129134, 133-138). The secondary structures of IGF2a were predicted by SOPMA, and the results showed that, in IGF2a, $\alpha$-helix accounts for $34.98 \%$; extended strand, $12.81 \%$; $\beta$-turn, $4.93 \%$, and random coil, $47.29 \%$. This finding indicated that $\alpha$-helices and random coils are dominant among the secondary structures of IGF2a, with small regions of extended strands and $\beta$-turns.

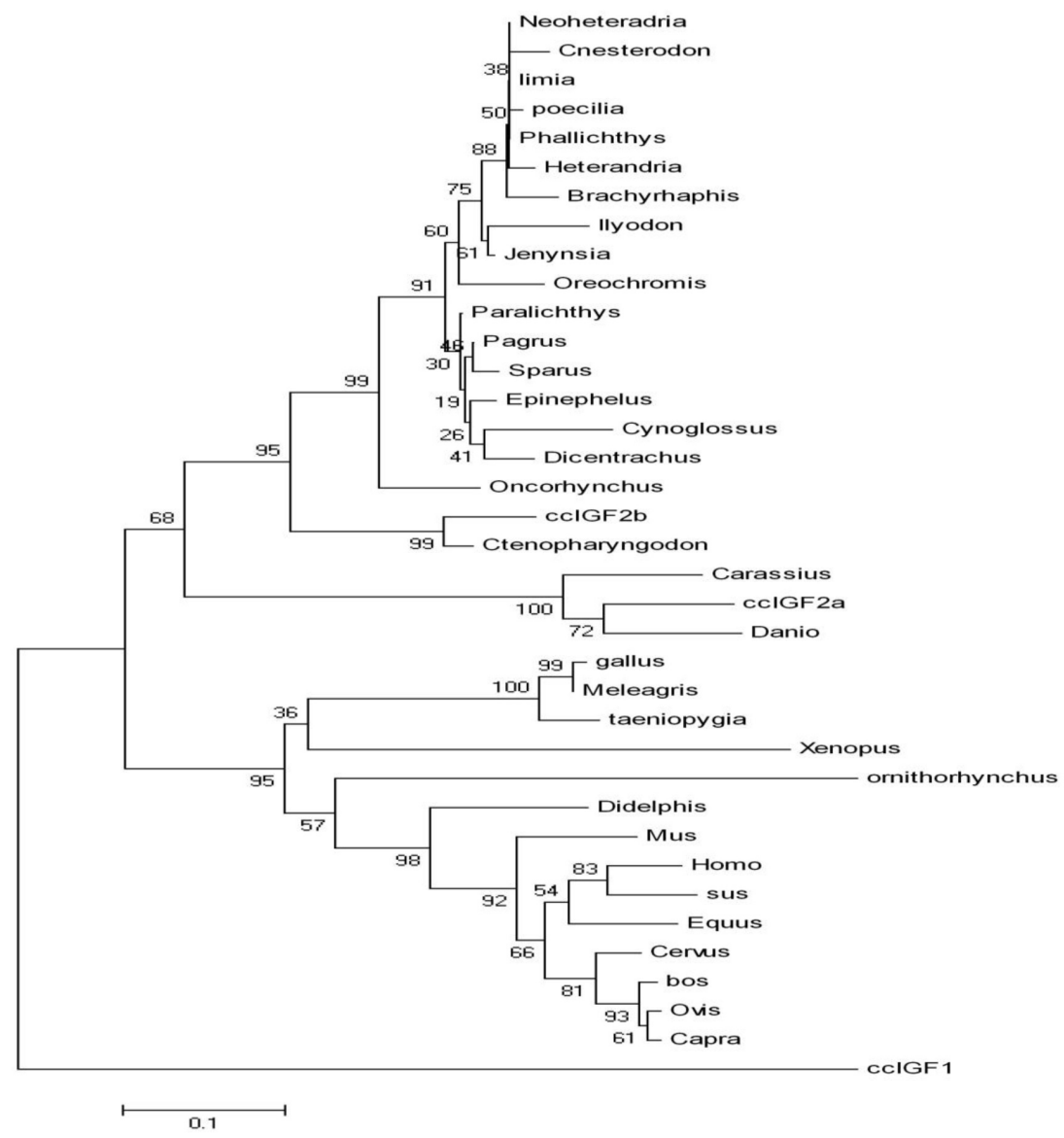

Figure 4. Unrooted phylogenetic tree of the deduced IGF2a protein sequence in Cyprinus carpio (HM641129) and the IGF2a protein sequence of other vertebrates: Cyprinus carpio (D83271), Danio rerio (NM_131433), Xenopus laevis (NM_001088659), Didelphis virginiana (AY552325), Ornithorhynchus anatinus (AY̌552324), Mus musculus (U71085), Oncorhynchus mykiss (M95184), Homo sapiens (J03242), Ovis aries (M89788), Sus scrofa (NM 213883), Bos taurus (NM 174087), Gallus gallus (NM 001030342), Taeniopygia guttata (AJ223165), Limia melanogaster (DQ337478), Poecilia butleri (DQ337477), Cnesterodon decemmaculatus (DQ337475), Brachyrhaphis rhabdophora (DQ337474), Phallichthys tico (DQ337472), Neoheterandria tridentiger (DQ337469), Jenynsia maculate (DQ337454), Ilyodon amecae (DQ337453), Equus caballus (NM_001114539), Capra hircus (GQ246165), Dicentrachus labrax (AY839105), Meleagris gallopavo (AY829236), Epinephelus coioides (AY552787), Paralichthys olivaceus (AF091454), Cynoglossus semilaevis (FJ608668), Carassius auratus (FJ410929), Pagrus auriga (AB362310), Oreochromis niloticus (EU272150), Sparus aurata (EF563836), Cervus elaphus (EF177491), Ctenopharyngodon idella (EF062860), and Heterandria formosa (AY833403). 


\section{Analysis of the $5^{\prime}$ flanking region of IGF2a}

The transcription start site for IGF2a at its $5^{\prime}$ flanking region was predicted using Promoter 2.0 and the Neural Network Promoter Prediction method. The former method found one 700-bp promoter, the latter detected 4 promoters (1472-1522, 1702-1752, 1847-1897, and 2326-2376). The canonical TATA box (1139 and 2574) of the 5 ' flanking region of the IGF2a gene was predicted using the TSSP program. No CpG island was identified by MethPrimer. The consensus binding sequences for several transcription factors, including v-Myb, AML-1a, SRY, CdxA, S8, Oct-1, C/EBP, C/EBPa, TATA, GATA-2, Nkx-2, XFD-3, HSF2, GATA-X, GATA-1, E2, C/EBPa, C/EBPb, Nkx-2, HFH-2, Lyf-1, MZF1, AP-1, Ik-2, HNF-3b, Sox-5, CRE-BP, CREB, E2F, Pbx-1, Nkx-2, GATA-3, c-Ets, VBP, ISRE, Pbx-1, Brn-2, STATx, HLF, E4BP4, Sox-5, CHOP-C, Tst-1, p300, XFD-3, HNF-3b, USF, CRE-BP, and c-Ets, were identified using TFSEARCH. Other transcription factors were also determined by ProScan (E4F1, ATF/CREB, ATF, c-fos_US5, EivF, EivF/CREB, E4TF1, and TFIID).

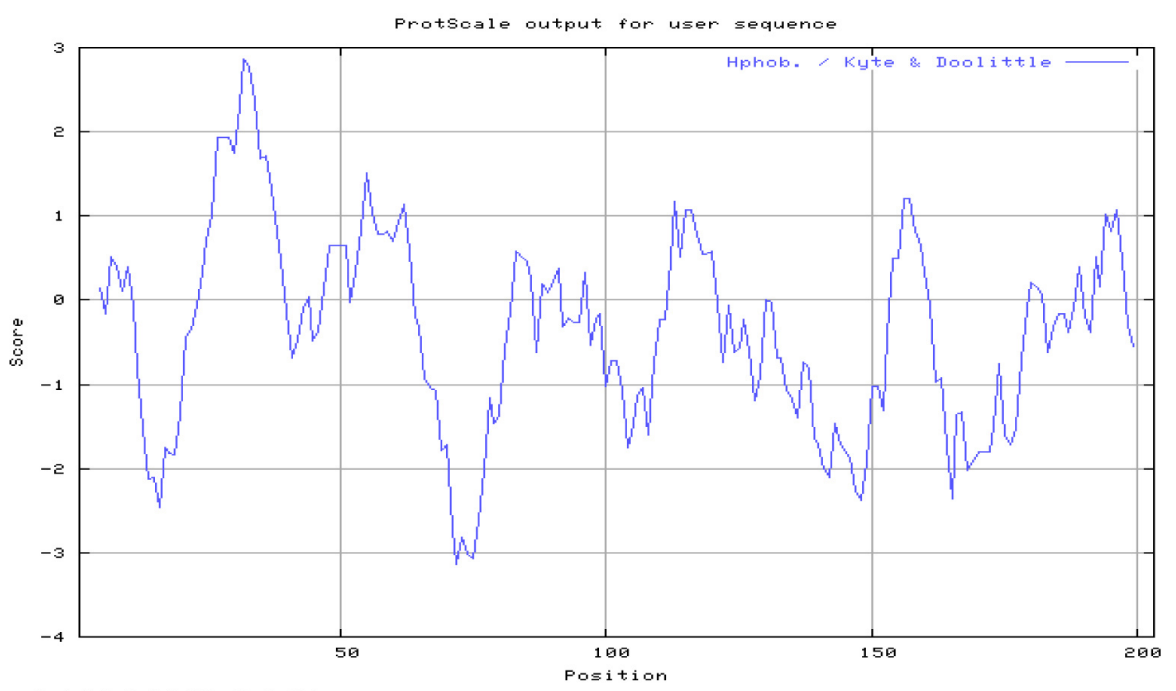

MIN: -3.133 MAX: 2.867

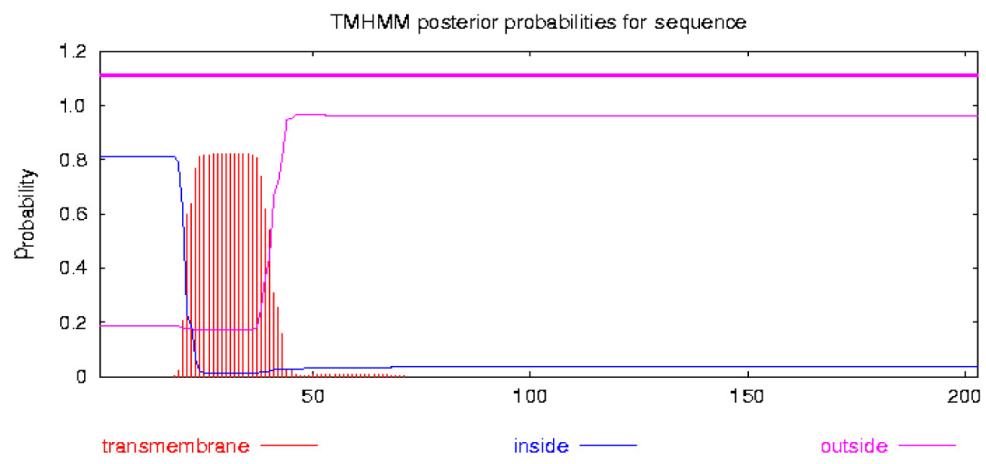

Figure 5. Hydrophobic residue analysis of the IGF2a polypeptide and transmembrane prediction. 


\section{SNP analysis}

We identified 2 new SNPs in intron 2 of the gene (Figure 6). One position, A/N, can be found only in the Huanghe carp, and not in the Jian carp or the crosses Huanghe carp $\widehat{x} \mathrm{x}$ Jian carp $\odot$, Jian $\operatorname{carp}^{\lambda} \mathrm{x}$ Huanghe carp + , or Huanghe $\operatorname{carp}^{\lambda} \mathrm{x}$ Heilongjiang carp ${ }^{\circ}$. In the Huanghe carp, the occurrence of the mutant genotype was not significant compared with that of the wild genotype. The other polymorphism, $\mathrm{C} / \mathrm{N}$, can be found in the Huanghe carp or the crosses Huanghe $\operatorname{carp}^{\hat{\lambda}} \mathrm{x}$ Jian carp $\uparrow$, Huanghe carp $\delta^{\hat{x}} \mathrm{x}$ Heilongjiang carp $q$ and Jian $\operatorname{carp} \hat{\delta} \mathrm{x}$ Huanghe carp 9 . However, only 1 individual had the mutant genotype in Jian carp $\widehat{x} \mathrm{x}$ Huanghe carp ${ }_{+}$, and the polymorphism was not observed in the Jian carp. Both the crosses Huanghe

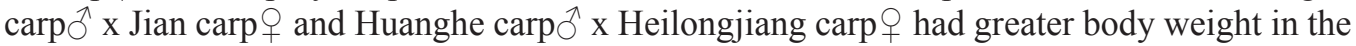
mutant form, but the Huanghe carp mutant had lower body weight.

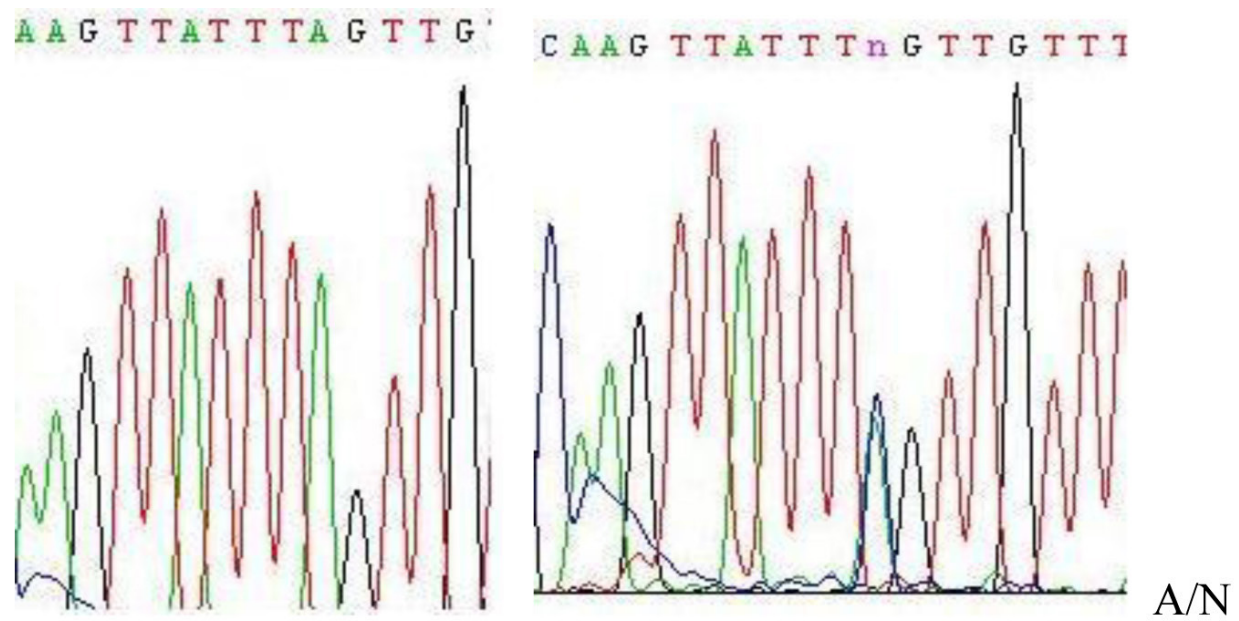

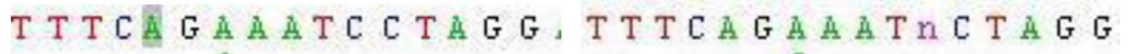

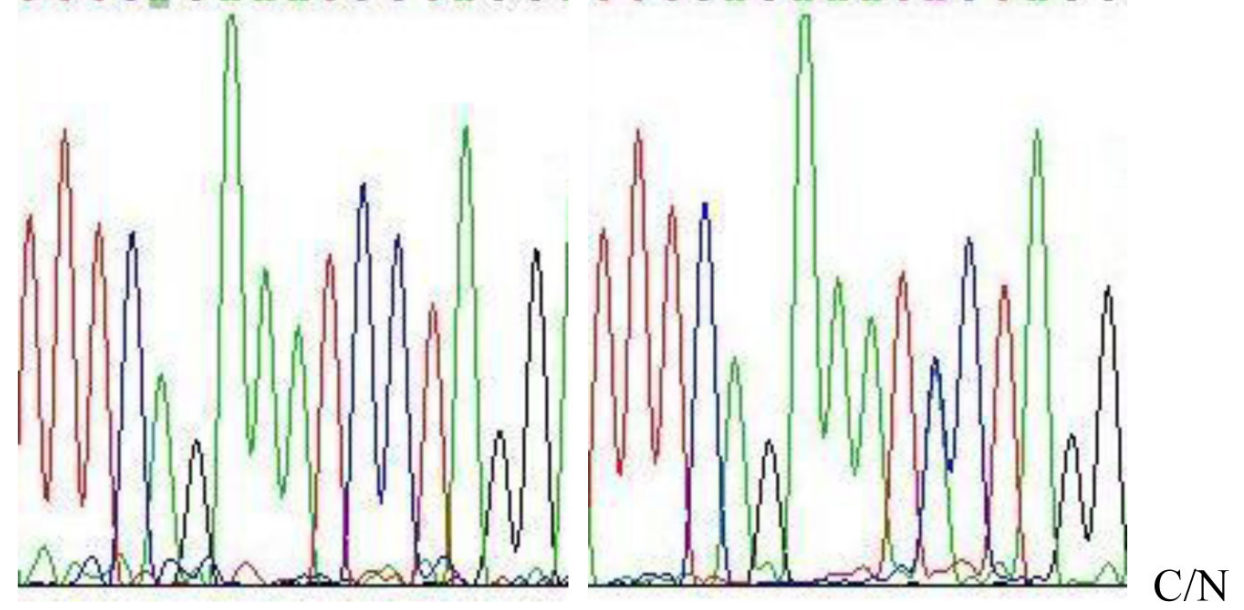

Figure 6. SNPs observed in 5 combinations of common carp. 


\section{DISCUSSION}

\section{Cloning and sequence analysis of IGF2a genes from the common carp muscle}

In the past, the common carp IGF2 was cloned (Tse et al., 2002). Furthermore, sequences of zebrafish $I G F 2 a$ and $I G F 2 b$ were got (Zou et al., 2009). So whether this gene cloned in common carp is $I G F 2 a$ or IGF2b? Actually can two peptides be achieved? BLAST analysis showed that the amino acid sequence of IGF2 of zebrafish shared high similarity with that of IGF2b. Based on this result, we cloned the common carp IGF2 (IGF2b) again. At the same time, $I G F 2 a$ was also cloned and characterized from the muscle of common carp. Full-length cDNA of IGF2a had a length of 2075 bp with a 612-bp ORF. The ORFs encoded a protein of 204 amino acids with a predicted molecular weight of $23.1 \mathrm{kDa}$. The amino acid sequences of IGF2a contain 5 signature sequence domains A-E. Among them, the domains A, $\mathrm{D}$, and $\mathrm{E}$ of IGF2a are more conserved than the corresponding domains of IGF2b (Tse et al., 2002). In addition, the alignment of amino acid sequences and phylogenetic analysis showed that the common carp IGF2a sequence is more closely related to the zebrafish IGF2a than it is to the carp IGF2b. In addition, the common carp IGF2a was close to other fish (such as Carassius auratus, Ctenopharyngodon idella) by phylogenetic analysis.

\section{Bioinformatics analysis}

Bioinformatics analysis indicates that the proteins encoded by IGF2a genes have 2 long stretches of hydrophobic residues and 1 signal peptide. The result is the same as that of zebrafish (NM_131433) predicted by TMHMM Server v. 2.0. The most probable cleavage site is between positions 42 and 43. Results of transmembrane analysis showed that, in IGF2a, $\alpha$-helix accounts for $34.98 \%$ of the structure; extended strand, $12.81 \% ; \beta$-turn, $4.93 \%$, and random coil, $47.29 \%$. These findings indicated that $\alpha$-helices and random coils are dominant in the secondary structure of IGF2a, with small regions of extended strands and $\beta$-turns.

These may be illustrated by the IGF2 immunostaining research, which was detected in the cytoplasm and on the membrane of positive mesenchymal cells (Steigen et al., 2009), but the result should be verified by crystal structure analysis (Dubnovitsky et al., 2010).

\section{SNP analysis}

In a previous study, both Huanghe carpo $\mathrm{x}$ Jian $\operatorname{carp} \propto$ and Jian $\operatorname{carp} \hat{\partial} \mathrm{x}$ Huanghe carp $\bigcirc$ showed overdominant heterosis. In the past, SNPs from IGF2 have been used to research meat quality and quantity of purebred and crossbred groups (Carrodeguas et al., 2005). This study has attempted to show the role of IGF2a SNPs in causing this heterosis. The A/N polymorphism can be found only in the Huanghe carp. However, the occurrence of the mutant genotype was not significant in comparison with that of the wild genotype. The other polymorphism, C/N, can be found in the Huanghe carp, Huanghe carp ${ }^{\lambda} \mathrm{x}$ Jian carp 9 , and Jian carp $\hat{x} \mathrm{x}$ Huanghe carp$\odot$, although it was not observed in the Jian carp. This implies that the polymorphism may be not transferred to $F_{1}$ progeny from the Huanghe carp. However, only 1 individual had the mutant genotype in Jian carp ${ }^{\lambda} \mathrm{x}$ Huanghe carp + , and this may suggest that the polymorphism is mainly transferred from the male. In order to verify this hypothesis, 
the Huanghe $\operatorname{carp}{ }^{\lambda} \mathrm{x}$ Heilongiiang $\operatorname{carp} \uparrow$ cross was used to analyze the mutant. The result showed that the mutant genotype was most common in this crosses. Both cross Huanghe $\operatorname{carp}^{\lambda} \mathrm{x}$ Jian carp $\odot$ and Huanghe carp ${ }^{\lambda} \mathrm{x}$ Heilongjiang carp $\odot$ had higher body weights in the mutant form; however, Huanghe carp mutants had lower body weight. This could be caused by epistasis related to heterosis.

In addition, the $I G F 2$ SNPs can be used to analyze linkage equilibrium with other genes such as MC4R (Burgos et al., 2006) and IGF2 transcript expression (Braunschweig et al., 2004).

\section{CONCLUSION}

Zou et al. (2009) found that zebrafish had full-length cDNAs encoding 2 structurally distinct IGF2 peptides (IGF2a and IGF2b), in which IGF2a had 4 exons. Similarly, the full-length cDNA sequence (2075 bp) and DNA sequence (6614 bp), including the 5' flanking region of IGF2a, were isolated. There were 4 exons and 3 introns in the IGF2a fragment. The amino acid sequence of $I G F 2 a$ shares high similarity with that of $I G F 2 b$. Two long stretches of hydrophobic residues are present in the IGF2a polypeptide. There is 1 signal peptide and 1 apparent transmembrane region in the common carp IGF2a. We identified 2 new SNPs in intron 2 of the gene. One of these, $\mathrm{A} / \mathrm{N}$, can be found only in the Huanghe carp. The other, $\mathrm{C} / \mathrm{N}$,

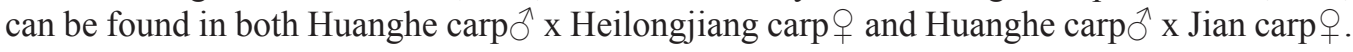
This may suggest that the polymorphism is primarily transferred from the male.

\section{ACKNOWLEDGMENTS}

Research supported by grants from the Earmarked Fund for Modern Agro-Industry Technology Research System (\#CARS-46), the National Nonprofit Institute Research Grant of CATAS-TCGRI (\#2009JBFB01) and the Natural Science Foundation of Jiangsu Province of China (\#BK2010164). We thank the students and staff of the Aquatic Genetic Laboratory, FFRC, for their kind assistance in the study.

\section{REFERENCES}

Aegerter S, Jalabert B and Bobe J (2004). Messenger RNA stockpile of cyclin B, insulin-like growth factor I, insulinlike growth factor II, insulin-like growth factor receptor $\mathrm{Ib}$, and p53 in the rainbow trout oocyte in relation with developmental competence. Mol. Reprod. Dev. 67: 127-135.

Ayson FG, de Jesus EG, Moriyama S, Hyodo S, et al. (2002). Differential expression of insulin-like growth factor I and II mRNAs during embryogenesis and early larval development in rabbitfish, Siganus guttatus. Gen. Comp. Endocrinol. 126: $165-174$.

Bobe J, Maugars G, Nguyen T, Rime H, et al. (2003). Rainbow trout follicular maturational competence acquisition is associated with an increased expression of follicle stimulating hormone receptor and insulin-like growth factor 2 messenger RNAs. Mol. Reprod. Dev. 66: 46-53.

Bondy CA, Werner H, Roberts CT Jr and LeRoith D (1990). Cellular pattern of insulin-like growth factor-I (IGF-I) and type I IGF receptor gene expression in early organogenesis: comparison with IGF-II gene expression. Mol. Endocrinol. 4: 1386-1398.

Braunschweig MH, Van Laere AS, Buys N, Andersson L, et al. (2004). IGF2 antisense transcript expression in porcine postnatal muscle is affected by a quantitative trait nucleotide in intron 3. Genomics 84: 1021-1029.

Burgos C, Carrodeguas JA, Moreno C, Altarriba J, et al. (2006). Allelic incidence in several pig breeds of a missense variant of pig melanocortin-4 receptor (MC4R) gene associated with carcass and productive traits; its relation to 
IGF2 genotype. Meat Sci. 73: 144-150.

Caelers A, Schmid AC, Hrusovsky A and Reinecke M (2003). Insulin-like growth factor II mRNA is expressed in neurones of the brain of the bony fish Oreochromis mossambicus, the tilapia. Eur. J. Neurosci. 18: 355-363.

Carrodeguas JA, Burgos C, Moreno C, Sánchez AC, et al. (2005). Incidence in diverse pig populations of an IGF2 mutation with potential influence on meat quality and quantity: An assay based on real time PCR (RT-PCR). Meat Sci. 71: 577-582.

Chauvigne F, Gabillard JC, Weil C and Rescan PY (2003). Effect of refeeding on IGFI, IGFII, IGF receptors, FGF2, FGF6, and myostatin mRNA expression in rainbow trout myotomal muscle. Gen. Comp. Endocrinol. 132: 209-215.

Chen JY, Chang CY, Chen JC, Shen SC, et al. (1997). Production of biologically active recombinant tilapia insulin-like growth factor-II polypeptides in Escherichia coli cells and characterization of the genomic structure of the coding region. DNA Cell Biol. 16: 883-892.

Collet C, Candy J, Richardson N and Sara V (1997). Organization, sequence, and expression of the gene encoding IGFII from barramundi (Teleosteii; Lates calcarifer). Biochem. Genet. 35: 211-224.

Dubnovitsky AP, Duck Z, Kersley JE, Hard T, et al. (2010). Conserved hydrophobic clusters on the surface of the Caf1A usher C-terminal domain are important for F1 antigen assembly. J. Mol. Biol. 403: 243-259.

Duguay SJ, Lai-Zhang J, Steiner DF, Funkenstein B, et al. (1996). Developmental and tissue-regulated expression of IGF-I and IGF-II mRNAs in Sparus aurata. J. Mol. Endocrinol. 16: 123-132.

Gabillard JC, Weil C, Rescan PY, Navarro I, et al. (2003). Effects of environmental temperature on IGF1, IGF2, and IGF type I receptor expression in rainbow trout (Oncorhynchus mykiss). Gen. Comp. Endocrinol. 133: 233-242.

Loffing-Cueni D, Schmid AC and Reinecke M (1999). Molecular cloning and tissue expression of the insulin-like growth factor II prohormone in the bony fish Cottus scorpius. Gen. Comp. Endocrinol. 113: 32-37.

Maures T, Chan SJ, Xu B, Sun H, et al. (2002). Structural, biochemical, and expression analysis of two distinct insulin-like growth factor I receptors and their ligands in zebrafish. Endocrinology 143: 1858-1871.

Nilsson C, Hultberg BM and Gammeltoft S (1996). Autocrine role of insulin-like growth factor II secretion by the rat choroid plexus. Eur. J. Neurosci. 8: 629-635.

Palamarchuk A, Gritsenko O, Holthuizen E, Sussenbach J, et al. (2002). Complete nucleotide sequence of the chum salmon insulin-like growth factor II gene. Gene 295: 223-230.

Perrot V, Moiseeva EB, Gozes Y, Chan SJ, et al. (2000). Insulin-like growth factor receptors and their ligands in gonads of a hermaphroditic species, the gilthead seabream (Sparus aurata): expression and cellular localization. Biol. Reprod. 63: 229-241.

Radaelli G, Patruno M, Maccatrozzo L and Funkenstein B (2003). Expression and cellular localization of insulin-like growth factor-II protein and mRNA in Sparus aurata during development. J. Endocrinol. 178: 285-299.

Rotwein P (1991). Structure, evolution, expression and regulation of insulin-like growth factors I and II. Growth Factors 5: 3-18.

Shamblott MJ and Chen TT (1992). Identification of a second insulin-like growth factor in a fish species. Proc. Natl. Acad. Sci. U. S. A. 89: 8913-8917.

Shamblott MJ, Cheng CM, Bolt D and Chen TT (1995). Appearance of insulin-like growth factor mRNA in the liver and pyloric ceca of a teleost in response to exogenous growth hormone. Proc. Natl. Acad. Sci. U. S. A. 92: 6943-6946.

Steigen SE, Schaeffer DF, West RB and Nielsen TO (2009). Expression of insulin-like growth factor 2 in mesenchymal neoplasms. Mod. Pathol. 22: 914-921.

Stinckens A, Mathur P, Janssens S, Bruggeman V, et al. (2010). Indirect effect of IGF2 intron3 g.3072G>A mutation on prolificacy in sows. Anim. Genet. 41: 493-498.

Tse MC, Vong QP, Cheng CH and Chan KM (2002). PCR-cloning and gene expression studies in common carp (Cyprinus carpio) insulin-like growth factor-II. Biochim. Biophys. Acta 1575: 63-74.

Vong QP, Chan KM and Cheng CH (2003). Quantification of common carp (Cyprinus carpio) IGF-I and IGF-II mRNA by real-time PCR: differential regulation of expression by GH. J. Endocrinol. 178: 513-521.

Yu J, Chen X, Li J, Tang Y, et al. (2010). Isolation of IGF2 and association of IGF2 polymorphism with growth trait in genetically improved farmed tilapias, Oreochromis niloticus L. Aquaculture Res. 41: e743-e750.

Zou S, Kamei H, Modi Z and Duan C (2009). Zebrafish IGF genes: gene duplication, conservation and divergence, and novel roles in midline and notochord development. PLoS One 4: e7026. 